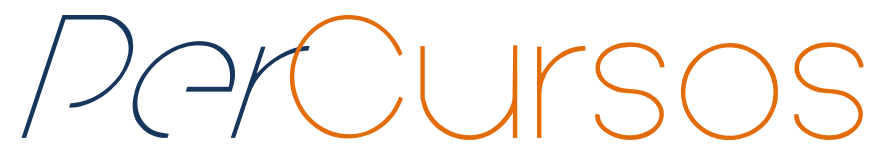

\title{
Transporte escolar e processos de institucionalização e gestão da educação em municípios do Tocantins
}

\begin{abstract}
Resumo
$\mathrm{O}$ artigo tem como objeto o transporte escolar e a gestão da educação em municípios do Tocantins, com o objetivo de discutir a possível relação entre transporte escolar e processos de institucionalização e gestão da educação municipal, sejam em redes de ensino ou em sistemas próprios de educação, de forma amostral, no âmbito do Tocantins. Com esta intenção, apreenderam-se informações em normas, políticas, programas, projetos e ações para o transporte escolar advindas do Ministério da Educação e na literatura da área da Educação relacionada ao transporte escolar no País; ainda, descreveu-se como municípios do Tocantins estão fazendo a gestão do transporte escolar. As dificuldades e problemas com a gestão do transporte escolar envolvem as ações de planejamento, organização/administração/execução, coordenação, manutenção/financiamento, articulação com atores sociais/comunidade, acompanhamento, fiscalização e avaliação. Merecem destaque a crença de que o transporte escolar é um benefício e não um direito de todos; e a tradicional inversão de pensamento em relação ao financiamento da educação, de que o recurso disponível deve ser suficiente para todas as despesas com as demandas, e não o contrário, de que as demandas é que devem definir os recursos. Por fim, defende-se a necessidade do enfrentamento da discussão em relação ao processo efetivo de institucionalização do sistema municipal de educação como instrumento de gestão pública para assegurar o direito à educação de qualidade social nos municípios.
\end{abstract}

Palavras-chave: Sistemas municipais de educação; Redes municipais de ensino; Política educacional; Direito à educação; Estado do Tocantins.

\section{Para citar este artigo:}

LAGARES, Rosilene; ROCHA, José Damião trindade; SANTOS, Jocycléia Santana dos. Transporte escolar e processos de institucionalização e gestão da educação em municípios do Tocantins. Revista PerCursos. Florianópolis, v. 15, n. 29, p. 138 -168, jul./dez. 2014.

DOI: 10.5965/1984724615292014138

http://dx.doi.org/10.5965/1984724615292014138 
School transport and procedures institutionalization and
management of education in
the municipalities Tocantins

\begin{abstract}
The article focuses school transport and the management of education in municipalities of Tocantins, in order to discuss the possible relationship between school and transport processes of institutionalization and administration of public education, whether in school systems or education systems themselves in sample form, under the Tocantins. With this intention, seized up information on standards, policies, programs, projects and activities for the school bus coming from the Ministry of Education; and literature in the field of education related to school transportation in the country; also described himself as municipalities Tocantins are making the management of school transport. The difficulties and problems with the management of school transport involve the actions of planning, organization / administration / implementation, coordination, maintenance / funding, liaison with social / community actors, monitoring, supervision and evaluation. Worth mentioning, the belief that school transportation is a benefit, not a right for all; and the reversal of traditional thinking regarding the financing of education, the remedy available should be sufficient for all expenditures with the demands, and not otherwise, is that the demands which must define the resources. Finally, we advocate the necessity of fighting the discussion about the actual process of institutionalization of the municipal education system as a tool for public management to ensure the right to education of social quality in municipalities.
\end{abstract}

Keywords: Municipal systems education; municipal education; educational policy; the right to education; State of Tocantins. 


\section{Introdução}

A educação é um direito de todos e o transporte escolar é um dos meios de viabilizá-la em iguais condições para todos, pelas gestões municipais e estaduais da educação, com o apoio financeiro e técnico da União.

Mas o que é gestão da/na Educação? Segundo Lagares (2005, p. 51-52), existem distintas maneiras de se conceber a gestão segundo o objeto do qual ela se ocupa, a concepção epistemológica, bem como o contexto social, político, econômico e cultural em que se insere. Nessa perspectiva, a gestão da/na Educação não é somente a técnica da administração. Nem somente a decisão política. Envolve duas questões, sendo a política e a administração. Hoje, ultrapassa as formas estritamente racionais, técnicas e mecânicas que a caracterizaram durante muitos anos sem, contudo, prescindir de alguns destes mecanismos, enquanto instrumentos necessários ao seu bom desenvolvimento e ao bom funcionamento da escola e do sistema de ensino. Isto, desde que estes instrumentos sejam compreendidos enquanto meios a serviço dos propósitos decididos coletivamente e expressos no projeto político educacional que cumpre, desta forma, sua função social e seu papel político-institucional.

Nesse sentido, ainda, conforme Lagares (2005, p. 54) uma gestão democrática, ética e de qualidade da educação implica "planejamento, organização, administração, manutenção, acompanhamento, fiscalização, avaliação de forma coletiva e cooperada, envolvendo as instâncias do Poder Público (Ministério da Educação, Conselho Nacional de Educação, Secretarias de Estado da Educação, Núcleos Regionais de Ensino, Conselhos Estaduais de Ensino, Secretarias ou Órgãos Municipais de Ensino, Conselhos Municipais de Educação, outros Conselhos na Educação, Instituições de Educação, Profissionais do Magistério e demais Trabalhadores da Educação) e a Sociedade".

Contudo, a despeito das orientações constitucionais e legais, e de estudos quanto à gestão democrática da/na Educação, o conjunto de projetos implementados, sobretudo a partir dos anos 1990, mostra a coexistência de uma pluralidade de propostas voltadas para esta gestão e da escola pública, as quais, muitas vezes, sob a mesma denominação 
formal de "gestão democrática", apresentam bases ideológicas diferenciais, o que aponta para a necessidade de seu “desvelamento".

Nesse processo de gestão da/na Educação, o município, a partir da promulgação da Constituição Federal de 1988 (BRASIL, 1988, art. 211, $\S 4^{\circ}$ ), passa a ser um ente federado autônomo e com atribuições específicas no campo da educação.

Nessa regulamentação e distribuição de responsabilidades entre as esferas públicas, a Lei de Diretrizes e Bases da Educação Nacional (LDB) nº 9.394/96 (BRASIL, 1996, art. 11, Parágrafo único) definiu que os municípios que não organizarem sistemas próprios de ensino, poderão optar por se integrar ao sistema estadual de ensino ou compor com ele um sistema único de educação básica.

No estado do Tocantins há municípios que estão constituindo seus sistemas de ensino, e que optam por continuar como rede de ensino do Sistema Estadual, e municípios que não se enquadram em nenhuma destas situações.

A LDB nº 9.394/96, com modificação pela Lei n 10.709/03 (BRASIL, 2003), definiu, em relação ao transporte escolar, como atribuição dos municípios, "assumir o transporte escolar dos alunos da rede municipal" (Art. 11, VI).

Isto posto, pergunta-se como os municípios do Tocantins estão fazendo a gestão do transporte escolar, bem como, se há alguma relação entre a forma de organização da educação municipal - em redes ou sistemas - e a gestão desse serviço. Em outras palavras, o objetivo é discutir a possível relação entre transporte escolar e processos de institucionalização e gestão da educação municipal, sejam em redes de ensino ou em sistemas próprios de educação, de forma amostral, no âmbito do Tocantins. Isto para subsidiar a regulação e a gestão dos serviços relacionados ao transporte escolar e, em consequência, o acesso, a permanência e a qualidade da educação básica.

Com esta intenção, foram trilhados caminhos bem específicos, sendo o conhecimento das normas, políticas, programas, projetos e ações para o transporte escolar advindos do Ministério da Educação (MEC), incluídos seus aspectos históricos, legais e de gestão; o exame da literatura da área da Educação relacionada ao transporte escolar no País; e a descrição dos modos pelos quais os municípios estão fazendo a gestão do transporte escolar, nos aspectos destacados por Lagares (2005, p. 54), sendo 
planejamento, organização, execução, financiamento, articulação com atores sociais, acompanhamento, fiscalização e avaliação.

Neste contexto, foram identificadas e examinadas as dificuldades, os fatores indicados pelos municípios em relação à gestão do transporte escolar; investigadas as relações existentes entre a gestão do transporte escolar e a situação de organização da educação nos municípios, em redes de ensino ou sistemas próprios de educação; examinada a existência ou não de formas de cooperação, a exemplo convênios ou outros instrumentos, entre o Sistema Estadual de Ensino e os respectivos municípios, para a gestão do transporte escolar, em especial, nas localidades em que não há sistemas próprios de educação. Também foram reunidos elementos, com base nos estudos e nas experiências dos municípios investigados, de modo a subsidiar a regulação e a gestão dos serviços relacionados ao transporte escolar e, em consequência, o acesso, a permanência e a qualidade da educação básica.

Para fins didáticos, este artigo está organizado em quatro seções, além desta introdução, articulando o método e a metodologia; os aspectos históricos, normativos e de gestão do transporte escolar; a gestão do transporte escolar nos municípios do Tocantins; e considerações finais.

\section{O caminho trilhado: fragmentos}

Para contextualizar a discussão empreendida neste artigo, observa-se que ela se origina de uma pesquisa desenvolvida entre julho e dezembro de 2011, como parte do Projeto de Pesquisa Transporte Escolar - Pesquisa Nacional Custo Aluno, desenvolvido pela Universidade de Brasília (UnB) e pela Universidade Federal do Tocantins (UFT), por meio do Núcleo de Estudos Contemporâneos (Necon UFT), com a gestão dos recursos financeiros pela Fundação de Apoio Científico e Tecnológico do Tocantins (Fapto), instituição financiadora, também, das bolsas de pesquisa. Ainda, é uma pesquisa ligada ao Subgrupo de Estudos, Pesquisa e Extensão em Educação Municipal da UFT (EpeEM-UFT).

Para a sua realização, optou-se por uma investigação abordando a gestão do transporte escolar em uma perspectiva histórico-social, a partir de suas origens e do 
contexto social, apresentando os dados e evidenciando seus nexos internos e contraditórios com a totalidade.

Reiteram-se, nesta realidade, as ideias de Ribeiro e Estelles (2009) a respeito da importante contribuição da análise de dados qualitativos em uma pesquisa relacionada ao transporte escolar rural, como um fator determinante para o alceamento de elementos que possam subsidiar políticas públicas sobre o tema.

Foi apreendida numericamente a frequência de ocorrência de determinadas ideias, temas, construções, referências e termos, para, em seguida, serem analisados do ponto de vista qualitativo, o que não caracteriza o estudo como quantitativo.

Assim, apreende-se a gestão do transporte escolar com objetivos explicativos, por uma abordagem qualitativa, com informações colhidas por meio de estudo documental, a respeito das normas, políticas, programas, projetos e ações para o transporte escolar do MEC; estudo bibliográfico, de literatura da área da educação relacionada ao transporte escolar no País; e pesquisa de campo, utilizando como instrumento um questionário semiestruturado, a partir das categorias “[...] planejamento, organização, execução, financiamento, articulação com atores sociais, acompanhamento, fiscalização e avaliação" (LAGARES, 2005, p. 54).

No Brasil, 451 municípios e o Distrito Federal (DF) compõem a amostra do Projeto de Pesquisa Transporte Escolar - Pesquisa Nacional Custo Aluno, selecionados com base em estudos anteriores pelo MEC (TOCANTINS, 2012).

Deste total, por orientações do coordenador da pesquisa em âmbito nacional, foram enviados questionários apenas para os municípios do estado do Tocantins que compõem a pesquisa em âmbito nacional, sendo um total de 21 localidades: Angico, Augustinópolis, Barra do Ouro, Barrolândia, Brejinho de Nazaré, Dianópolis, Dueré, Esperantina, Guaraí, Itaporã do Tocantins, Lagoa do Tocantins, Lajeado, Luzinópolis, Maurilândia do Tocantins, Miracema do Tocantins, Palmeiras do Tocantins, Ponte Alta do Bom Jesus, Rio Sono, Sítio Novo do Tocantins, Taguatinga e Wanderlândia, as quais foram avaliadas durante o período compreendido entre outubro e novembro de 2011.

Dos 21 municípios do Tocantins, que receberam os questionários, enviados por email com o apoio da União Nacional dos Dirigentes Municipais de Educação (Undime), 
cinco os devolveram, sendo Dueré (região sul), Palmeiras do Tocantins (região norte), Ponte Alta do Bom Jesus (região sudeste), Rio dos Bois (região norte) e Rio Sono (região central).

Analisadas as informações da pesquisa, elas foram comparadas com as recolhidas na bibliografia e nos documentos estudados, bem como comparados os dados dos e entre os próprios municípios. Especificamente, quanto aos questionários, a análise, inicialmente, ocorreu em uma perspectiva quantitativa, apreendendo-se numericamente a frequência de ocorrência de determinadas ideias, temas, construções, referências e termos, para, em seguida, serem analisados do ponto de vista qualitativo.

\section{Transporte escolar: aspectos históricos, normativos e de gestão}

Normas, políticas, programas, projetos e ações do Ministério da Educação para o transporte escolar

Criado com o nome de Transporte de Escolares, este direito tinha como função inicial levar alunos que moravam na zona rural até a escola mais próxima.

Em termos normativos, as diretrizes para o transporte escolar estão definidas na Constituição Federal de 1988 (BRASIL, 1988), Art. 208, VII, como um dos programas suplementares, sob a responsabilidade do Poder Público, no cumprimento de seu dever com a educação; em especial, o ensino fundamental.

Em 1994, é criado o Programa Nacional de Transporte Escolar (PNTE), segundo o Plano Nacional de Transporte Escolar: Nota Técnica (BRASIL, 2001), por meio da Portaria Ministerial n 955, de 21 de junho de 1994 (BRASIL, 1994), no âmbito do MEC, com verba do Fundo Nacional de Desenvolvimento da Educação (Fnde), para contribuir com o transporte dos alunos no trajeto residência-escola-residência. Em outras palavras, para contribuir financeiramente com os municípios e Organizações Não Governamentais (Ongs) para a aquisição de veículos automotores zero quilômetro, destinados ao transporte diário dos alunos da rede pública de ensino fundamental, residentes na área rural, e das escolas de ensino fundamental que atendam alunos com algum tipo de deficiência. 
No período compreendido entre 1995 e 2003, o PNTE foi gerido por meio de Convênios.

Nos anos de 1995 e 1996, esta iniciativa contemplou os municípios priorizados pelo Programa Comunidade Solidária. A partir de 1997, o atendimento foi direcionado para os demais municípios e àqueles que comprovassem consolidação, aglutinação ou nucleação de escolas. Em 1998, foram atendidos 1.558 municípios em todo o País, em decorrência de um substancioso repasse de verbas. No ano de 1999, o Programa não pode ser executado por razões orçamentárias, e no ano de 2000 houve uma retomada significativa, atendendo 230 ONGs e 961 municípios.

Em 1996, a Lei de Diretrizes e Bases da Educação Nacional (LDB) nº 9.394 (BRASIL, 1996), da mesma forma que a Constituição Federal de 1988, define o transporte escolar como um programa suplementar para o ensino fundamental público, como dever do Estado com a educação escolar pública (Art. $\left.4^{\circ}, \mathrm{VIII}\right)$.

A LDB $n^{\circ}$ 9.394/96 considera a manutenção de programas de transporte escolar como de manutenção e desenvolvimento do ensino, ou seja, como despesas realizadas com vistas à consecução dos objetivos básicos das instituições educacionais de todos os níveis de educação e ensino (Art. 70, VIII).

Com base no documento Plano Nacional de Transporte Escolar: Nota Técnica (BRASIL, 2001), em 1995,foram atendidos312 municípios; em 1996, 623; em 1997, 414; em 1998, 1.558; e em 2000, 1.191 municípios.

Em 2001, a Resolução do Fundo Nacional de Desenvolvimento da Educação (FNDE) $\mathrm{n}^{\circ} 28$, de 28 de junho (BRASIL, 2001), estabeleceu orientações e diretrizes para a assistência financeira suplementar aos projetos educacionais no âmbito do PNTE.

O Plano Nacional de Transporte Escolar: Nota Técnica (BRASIL, 2001, p. 3-4), explicita que o objetivo do programa é a assistência financeira aos municípios e organizações não governamentais para a aquisição de veículos novos destinados, exclusivamente, ao transporte dos alunos matriculados nas escolas da rede pública estadual e municipal, de ensino fundamental e da educação especial, prioritariamente, residentes no meio rural, de modo a garantir o acesso e a permanência dos alunos na escola, erradicando a evasão escolar. 
Em 2003, a LDB nº 9.394/96 é modificada pela Lei n 10.709, de 31/7/2003 (BRASIL, 2003), que divide a responsabilidade com a gestão do Programa de Transporte Escolar entre os estados, que são os responsáveis por assumir o transporte escolar dos alunos da rede estadual (Art. 10, VII) e os municípios, pelo transporte escolar dos alunos da rede municipal (Art. 11, VI).

A Lei $n^{\circ} 10.709 / 03$ define, também, que cabe aos estados articular-se com os respectivos municípios, para prover o disposto em seu texto da forma que melhor atender aos interesses dos alunos (Art. $\left.3^{\circ}\right)$.

Em 2004, é instituído o Programa Nacional de 'Apoio' ao Transporte Escolar (Pnate), com gestão por meio de Transferência Direta, não mais com Convênios, sendo normatizado pela Lei $n^{\circ} 10.880$, de 9 de junho de 2004 (BRASIL, 2004).

Nesta Lei, o objetivo do Pnate é garantir o acesso e a permanência nos estabelecimentos escolares dos alunos do ensino fundamental público, residentes em área rural que utilizem transporte escolar, por meio de assistência financeira, em caráter suplementar, aos estados, Distrito Federal e municípios (BRASIL, 2004).

O referido Programa passa a atender somente às ONGs sem fins lucrativos que mantinham escolas especializadas de ensino fundamental, com até cem alunos com algum tipo de deficiência. As entidades recebiam, em uma única parcela, o valor máximo de $\mathrm{R} \$ 35.000,00$, mediante celebração de convênio, para aquisição de veículo escolar zero quilômetro, com capacidade mínima para nove passageiros. Em 2006, para ser atendida, a entidade não poderia ter sido contemplada nos últimos três anos (BRASIL, 2004).

Em 2007, foi criado o Programa Caminho da Escola, pela Resolução $n^{\circ}$ 3, de 28 de março (BRASIL, 2007), consistindo na concessão, pelo Banco Nacional de Desenvolvimento Econômico e Social (BNDES), de linha de crédito especial para a aquisição, pelos estados e municípios, de ônibus, miniônibus e micro-ônibus zero quilômetro e de embarcações novas.

O governo federal, por meio do FNDE e em parceria com o Instituto Nacional de Metrologia, Qualidade e Tecnologia (Inmetro), oferece um veículo com especificações exclusivas, próprias para o transporte de estudantes, e adequado às condições de trafegabilidade das vias das zonas rural e urbana brasileira. 
O Programa Caminho da Escola consiste na aquisição, por meio de pregão eletrônico, para registro de preços realizados pelo FNDE, de veículos padronizados para o transporte escolar. Estados e municípios podem participar do Programa por três meios: a) com recursos próprios dos entes federados, bastando aderir ao pregão; b) por meio de convênio firmado com o FNDE; ou c) por meio de linha de crédito especial/empréstimo do BNDES.

Em 2009, o Pnate foi ampliado para toda a Educação Básica (educação infantil, ensino fundamental e ensino médio), aos alunos residentes em áreas rurais, com a gestão dos recursos por transferência automática, com a Medida Provisória 455/2009 transformada na Lei $n^{\circ} 11.947$, de 16 de junho de 2009 (BRASIL, 2009).

Em 2011, O MEC executa dois programas voltados ao transporte de estudantes, sendo o Caminho da Escola e o Pnate, os quais visam atender alunos moradores do meio rural.

O Pnate consiste na transferência automática de recursos financeiros, sem necessidade de convênio ou outro instrumento congênere, para custear despesas com reforma, seguros, licenciamento, impostos e taxas, pneus, câmaras, serviços de mecânica em freio, suspensão, câmbio, motor, elétrica e funilaria, recuperação de assentos, combustível e lubrificantes do veículo ou, no que couber, da embarcação utilizada para o transporte de alunos da educação básica pública, residentes em áreas rurais. Serve, também, para o pagamento de serviços contratados junto a terceiros para o transporte escolar.

Os estados podem autorizar o FNDE a efetuar o repasse do valor correspondente aos alunos da rede estadual diretamente aos respectivos municípios. Para isso, é necessário formalizar a autorização por meio de ofício ao órgão. Caso não o façam, terão de executar diretamente os recursos recebidos, ficando impedidos de fazer transferências futuras aos entes municipais.

O transporte escolar em literaturas da Educação

O Grupo de Estudos em Empresa Brasileira de Planejamento de Transportes (GEIPOT, 1995), extinto pela Medida Provisória $n^{\circ}$ 427, de 09 de maio de 2008, estudou e pesquisou inúmeros aspectos do Transporte Rural, abordando alguns em especial: a 
inevitabilidade da oferta do transporte rural escolar; o transporte rural escolar no orçamento municipal; a gratuidade do transporte rural escolar; a terceirização do transporte rural escolar (uma tendência); a opção entre empresas ou profissionais autônomos na terceirização (sendo a última a mais praticada); veículos para o transporte rural escolar (muitos tipos são inadequados, ilegais e inseguros, não oferecendo um mínimo de conforto e higiene às crianças e adolescentes);licitações para o transporte rural escolar (devem ser adequadas, pois a metodologia tradicional não pode ser aplicada para a locação de veículos escolares, pois conduz à estimativa de custos muito acima dos preços praticados); custo médio por aluno transportado por dia (que a questão seja sempre colocada em termos de custo diário, para diminuir as indefinições no processo de cálculo).

Feijó (2011) representa ideias de vários pesquisadores da área ao abordar o transporte escolar como dever do Estado, para a garantia de acesso e permanência do educando no ambiente escolar, considerando que a simples disponibilização do ensino público e gratuito é insuficiente para assegurar o acesso e a permanência da criança e do jovem na escola.

E foi pensando nessa realidade, acrescenta a autora, que o legislador constituinte atrelou ao dever de oferecer a educação, outras obrigações que se podem chamar de “acessórias”, mas que, na verdade, complementam o direito ao ensino público e por meio das quais se possibilita o acesso e a permanência do educando no ambiente escolar.

Segundo Martins (2010), a bibliografia desvela como dificuldades/problemas os longos tempos de viagens, as distâncias percorridas, os aspectos físicos do transporte e as condições das vias.

Santos (2010) explicita que o transporte escolar é importante porque facilita e favorece a educação dos alunos atendidos, o acesso à escola e à vida familiar. No entanto, destaca alguns aspectos negativos, apontados por gestores e planejadores/operadores, como os veículos/frotas são inadequados; as vias possuem péssimas condições de trafegabilidade; a quantia de recursos é insuficiente; e a população (alunos, pais e comunidade em geral) não compreende e não colabora com o transporte escolar rural. 
Em síntese, para pesquisadores do campo democrático popular, a gestão do transporte escolar é de responsabilidade de todos os entes federados, sendo um direito e um dever da população, ao passo que esta deve compor os conselhos que acompanharão a gestão deste serviço.

Programa transporte escolar com gestão descentralizada no País: União, Estados, Distrito Federal, Municípios e Conselhos

A gestão do Programa Transporte Escolar, com base em informações disponibilizadas no site do MEC, é realizada de forma descentralizada, com a distribuição de competências entre a União, os Estados, DF, Municípios e Conselhos de Acompanhamento e Controle Social do Fundo de Manutenção e Desenvolvimento da Educação Básica e de Valorização dos Profissionais da Educação (CACS-Fundeb).

No âmbito da União, o FNDE é o órgão responsável pela assistência financeira, normatização, coordenação, acompanhamento, fiscalização, cooperação técnica e avaliação da efetividade da aplicação dos recursos financeiros do Programa, diretamente ou por delegação de competência.

Nas Secretarias de Educação dos estados, do Distrito Federal e nos municípios estão os entes executores (Eex), responsáveis pelo recebimento e execução dos recursos financeiros transferidos pelo FNDE à conta do Pnate.

A prestação de contas é de responsabilidade das Secretarias de Educação de estados e dos municípios, devendo ser feita até o dia 28 de fevereiro de cada ano, para enviar ao CACS-Fundeb a prestação de contas dos recursos financeiros recebidos do Pnate no exercício anterior, acompanhada de toda a documentação constante da Resolução do FNDE que regulamenta o Programa.

Os CACS-Fundeb analisam os documentos e as prestações de contas, podendo solicitar às secretarias estaduais e municipais outros documentos que julgarem convenientes para subsidiar a análise da prestação de contas do Pnate. 
Depois da análise, os CACS-Fundeb emitem pareceres sobre a prestação de contas e os remetem ao FNDE, até o dia 15 de abril do mesmo ano, acompanhado da documentação.

\section{A gestão do transporte escolar em municípios do Tocantins}

\section{Contextualização}

Os cinco municípios que responderam ao questionário são de regiões distintas do Tocantins, sendo dois da região norte (Palmeiras do Tocantins e Rio dos Bois), um da região sul (Dueré), um da sudeste (Ponte Alta do Bom Jesus) e um da região central (Rio Sono). Responderam ao questionário quatro secretários municipais de educação e o coordenador de Programas e Projetos Educacionais da Secretaria Municipal de Educação; todos os cinco respondentes são graduados em Pedagogia. A população dos municípios varia de 2.500 a 6.000 habitantes; sua principal atividade econômica é a agropecuária; e todos se constituem em rede de ensino do Sistema Estadual de Ensino.

Com relação à oferta de transporte escolar rural no Estado do Tocantins, as Prefeituras são responsáveis pela execução do transporte escolar dos alunos matriculados nas escolas municipais e o Estado, por meio da Secretaria de Educação (Seduc), é responsável pela execução do transporte escolar dos alunos matriculados nas escolas estaduais, conforme disposto no art. 10, inciso VII e art. 11, inciso VI, da Lei $\mathrm{n}^{\circ}$. 9.394/96 - LDB (TOCANTINS, 2014a).

Para que seja feito o transporte escolar dos alunos da Rede Pública Estadual de Ensino, a Seduc, “[...] em conformidade com a Lei $n^{\circ}$. 1.616, de 13 de outubro de 2005, repassa os recursos automaticamente aos Municípios, sem a necessidade de formalizar convênio. No entanto, há a obrigatoriedade de apresentar a prestação de contas, conforme mandamento constitucional e normas internas desta Secretaria." (TOCANTINS, 2014a).

Em 2014, para cobrir os custos com a manutenção do Transporte Escolar, a Secretaria, por meio do Programa de Manutenção do Transporte Escolar repassará os recursos financeiros às Prefeituras Municipais, em dez parcelas, para cobrir despesas com 
manutenção. As transferências são efetuadas a partir dos valores estabelecidos para cada Unidade Executora, quando é elaborado o Cronograma de Desembolso, anual, contendo os valores das parcelas a serem repassados, disponibilizado às Prefeituras (TOCANTINS, 2014a).

Asseis tabelas que seguem demonstram, de modo ilustrativo, a situação da oferta de educação básica no Tocantins, em termos de repartição de matrículas entre rede estadual e as redes municipais investigadas, com destaque para o espaço rural, como disposto no Censo Escolar de 2013 (BRASIL, 2013).

Tabela 1. Repartição de matrículas entre a rede estadual e as redes municipais no Tocantins

\begin{tabular}{|c|c|c|c|c|c|c|c|c|c|}
\hline \multirow{3}{*}{\multicolumn{2}{|c|}{ Esfera }} & \multicolumn{4}{|c|}{ Educação Infantil } & \multicolumn{4}{|c|}{ Ensino Fundamental } \\
\hline & & \multicolumn{2}{|c|}{ Creche } & \multicolumn{2}{|c|}{ Pré-Escolas } & \multicolumn{2}{|c|}{ Anos Iniciais } & \multicolumn{2}{|c|}{ Anos Finais } \\
\hline & & Parcial & Integral & Parcial & Integral & Parcial & Integral & Parcial & Integral \\
\hline \multirow[t]{2}{*}{ Estado } & Urbano & 0 & 0 & 0 & 0 & 24.065 & 12.265 & 51.263 & 19.596 \\
\hline & Rural & 0 & 0 & 0 & 0 & 3.161 & 1.224 & 3.436 & 1.799 \\
\hline \multirow[t]{2}{*}{ Município } & Urbano & 5.106 & 9.338 & 25.939 & 1.546 & 47.809 & 18.046 & 14.474 & 6.336 \\
\hline & Rural & 284 & 135 & 4.058 & 173 & 14.871 & 2.686 & 6.514 & 1.791 \\
\hline
\end{tabular}

Fonte: BRASIL. INEP, Censo Escolar 2013.

Percentualmente, na educação infantil, o Município atende, no campo e no meio urbano, $100 \%$ das matrículas. Já no ensino fundamental, nos anos iniciais urbano, o Município oferta 64,45\% e o Estado 35,55\% das matrículas. No campo, o Município oferece 80,01\%, ficando o Estado com 19,99\%. Por fim, nos anos finais, a situação de oferecimento das matrículas no meio urbano se inverte, ou seja, o Município atende22,70\% e o Estado 77,30\%. Contudo, ao contrário, no campo, o Município oferta 61,34\% e o Estado 38,66\%.

Da análise dos dados, é possível obter a informação de que a esfera pública municipal é a responsável pela oferta de toda a educação infantil tanto rural quanto urbana e, ao mesmo tempo, concentra a maior parte das matrículas no ensino fundamental, somando $57,12 \%$, enquanto o Estado oferece $42,88 \%$, reforçando a tese da forjada municipalização do ensino a partir dos anos 1990.

Tabela 2. Repartição de matrículas entre a rede estadual e a rede municipal de educação 
de Dueré

\begin{tabular}{|c|c|c|c|c|c|c|c|c|c|}
\hline \multicolumn{2}{|c|}{ Esfera } & \multicolumn{4}{|c|}{ Educação Infantil } & \multicolumn{4}{|c|}{ Ensino Fundamental } \\
\hline & & \multicolumn{2}{|c|}{ Creche } & \multicolumn{2}{|c|}{ Pré-Escolas } & \multicolumn{2}{|c|}{ Anos Iniciais } & \multicolumn{2}{|c|}{ Anos Finais } \\
\hline & & Parcial & Integral & Parcial & Integral & Parcial & Integral & Parcial & Integral \\
\hline \multirow[t]{2}{*}{ Estado } & Urbano & 0 & 0 & 0 & 0 & 15 & 14 & 192 & 90 \\
\hline & Rural & 0 & 0 & 0 & 0 & 0 & 0 & 0 & 0 \\
\hline \multirow{2}{*}{$\begin{array}{l}\text { Município } \\
\text { Dueré }\end{array}$} & Urbano & 0 & 0 & 119 & 0 & 206 & 126 & 0 & 0 \\
\hline & Rural & 0 & 0 & 3 & 0 & 7 & 0 & 0 & 0 \\
\hline
\end{tabular}

Fonte: BRASIL. INEP, Censo Escolar 2013.

Tabela 3. Repartição de matrículas entre a rede estadual e a rede municipal de educação de Palmeiras do Tocantins

\begin{tabular}{|c|c|c|c|c|c|c|c|c|c|}
\hline \multirow{2}{*}{\multicolumn{2}{|c|}{ Esfera }} & \multicolumn{4}{|c|}{ Educação Infantil } & \multicolumn{4}{|c|}{ Ensino Fundamental } \\
\hline & & \multicolumn{2}{|c|}{ Creche } & \multicolumn{2}{|c|}{ Pré-Escolas } & \multicolumn{2}{|c|}{ Anos Iniciais } & \multicolumn{2}{|c|}{ Anos Finais } \\
\hline & & Parcial & Integral & Parcial & Integral & Parcial & Integral & Parcial & Integral \\
\hline \multirow[t]{2}{*}{ Estado } & Urbano & 0 & 0 & 0 & 0 & 40 & 64 & 231 & 230 \\
\hline & Rural & 0 & 0 & 0 & 0 & 0 & 0 & 0 & 0 \\
\hline \multirow{2}{*}{$\begin{array}{l}\text { Município } \\
\text { Palmeiras } \\
\text { do } \\
\text { Tocantins }\end{array}$} & Urbano & 0 & 0 & 120 & 0 & 309 & 0 & 0 & 0 \\
\hline & Rural & 0 & 0 & 59 & 0 & 155 & 0 & 0 & 0 \\
\hline
\end{tabular}

Fonte: BRASIL. INEP, Censo Escolar 2013.

Tabela 4. Repartição de matrículas entre a rede estadual e a rede municipal de educação de Ponte Alta do Bom Jesus

\begin{tabular}{|c|c|c|c|c|c|c|c|c|c|}
\hline \multirow{2}{*}{\multicolumn{2}{|c|}{ Esfera }} & \multicolumn{4}{|c|}{ Educação Infantil } & \multicolumn{4}{|c|}{ Ensino Fundamental } \\
\hline & & \multicolumn{2}{|c|}{ Creche } & \multicolumn{2}{|c|}{ Pré-Escolas } & \multicolumn{2}{|c|}{ Anos Iniciais } & \multicolumn{2}{|c|}{ Anos Finais } \\
\hline & & Parcial & Integral & Parcial & Integral & Parcial & Integral & Parcial & Integral \\
\hline \multirow[t]{2}{*}{ Estado } & Urbano & 0 & 0 & 0 & 0 & 159 & 104 & 249 & 49 \\
\hline & Rural & 0 & 0 & 0 & 0 & 44 & 0 & 52 & 0 \\
\hline \multirow{2}{*}{$\begin{array}{l}\text { Município } \\
\text { Ponte } \\
\text { Alta do } \\
\text { Bom } \\
\text { Jesus }\end{array}$} & Urbano & 31 & 0 & 80 & 0 & 0 & 0 & 0 & 0 \\
\hline & Rural & 0 & 0 & 0 & 0 & 173 & 0 & 117 & 0 \\
\hline
\end{tabular}

Fonte: BRASIL. INEP, Censo Escolar 2013.

Tabela 5. Repartição de matrículas entre a rede estadual e a rede municipal de educação de Rio dos Bois

\begin{tabular}{|l|l|l|l|l|l|l|l|l|l|}
\hline \multirow{2}{*}{ Esfera } & \multicolumn{4}{|c|}{ Educação Infantil } & \multicolumn{4}{c|}{ Ensino Fundamental } \\
\cline { 3 - 10 } & \multicolumn{2}{|c|}{ Creche } & \multicolumn{2}{c|}{ Pré-Escolas } & \multicolumn{2}{c|}{ Anos Iniciais } & \multicolumn{2}{c|}{ Anos Finais } \\
\cline { 3 - 10 } & Parcial & Integral & Parcial & Integral & Parcial & Integral & Parcial & Integral \\
\hline \multirow{2}{*}{ Estado } & Urbano & 0 & 0 & 0 & 0 & 148 & 0 & 193 & 0 \\
\cline { 2 - 10 } & Rural & $\mathbf{0}$ & $\mathbf{0}$ & $\mathbf{0}$ & $\mathbf{0}$ & $\mathbf{0}$ & $\mathbf{0}$ & $\mathbf{0}$ & $\mathbf{0}$ \\
\hline
\end{tabular}




\begin{tabular}{|l|l|l|l|l|l|l|l|l|l|}
\hline $\begin{array}{l}\text { Município } \\
\text { Rio dos } \\
\text { Bois }\end{array}$ & Urbano & 18 & 0 & 61 & 0 & 19 & 0 & 0 & 0 \\
\cline { 2 - 9 } & Rural & $\mathbf{0}$ & $\mathbf{0}$ & $\mathbf{1 3}$ & $\mathbf{0}$ & $\mathbf{8 3}$ & $\mathbf{0}$ & $\mathbf{0}$ & $\mathbf{0}$ \\
\hline
\end{tabular}

Fonte: BRASIL. INEP, Censo Escolar 2013.

Tabela 6. Repartição de matrículas entre a rede estadual e a rede municipal de educação de Rio Sono

\begin{tabular}{|c|c|c|c|c|c|c|c|c|c|}
\hline \multirow{3}{*}{\multicolumn{2}{|c|}{ Esfera }} & \multicolumn{4}{|c|}{ Educação Infantil } & \multicolumn{4}{|c|}{ Ensino Fundamental } \\
\hline & & \multicolumn{2}{|c|}{ Creche } & \multicolumn{2}{|c|}{ Pré-Escolas } & \multicolumn{2}{|c|}{ Anos Iniciais } & \multicolumn{2}{|c|}{ Anos Finais } \\
\hline & & Parcial & Integral & Parcial & Integral & Parcial & Integral & Parcial & Integral \\
\hline \multirow[t]{2}{*}{ Estado } & Urbano & 0 & 0 & 0 & 0 & 145 & 107 & 130 & 98 \\
\hline & Rural & 0 & 0 & 0 & 0 & 4 & 76 & 43 & 32 \\
\hline \multirow{2}{*}{$\begin{array}{l}\text { Município } \\
\text { Rio Sono }\end{array}$} & Urbano & 35 & 0 & 85 & 0 & 0 & 0 & 0 & 0 \\
\hline & Rural & 12 & 0 & 60 & 0 & 216 & 46 & 84 & 44 \\
\hline
\end{tabular}

Fonte: BRASIL. INEP, Censo Escolar 2013.

Nas cinco redes investigadas, com base no Censo Escolar de 2013 (BRASIL, 2013), o transporte escolar foi oferecido a 1.323 (hum mil trezentos e vinte e três) alunos, sendo 251 (duzentos e cinquenta e um) do Sistema Estadual, correspondendo a 18,97\%, e, nas redes municipais, 1.072 (hum mil e setenta e dois) alunos, correspondendo a $81,03 \%$ do atendimento. O que indica que o Município é o responsável pelo maior percentual na tarefa do transporte escolar.

Em 2014, com base no estabelecimento de Convênios entre a Seduc e as Prefeituras, estão sendo atendidos, pelos Municípios investigados, 715 (setecentos e quinze) alunos do Sistema Estadual de Ensino (TOCANTINS, 2014b). Os Convênios são justificados como instrumentos para "Estabelecer e regulamentar parceria, visando formalizar o repasse de recursos financeiros da CONCEDENTE para a CONVENENTE [...] para subsidiar o oferecimento de transporte escolar aos alunos da zona rural matriculados na rede pública de ensino [da educação básica]":

. Dueré - valor de R\$73.000,00 (setenta e três mil reais), para atender 73 (setenta e três) alunos.

- Palmeiras do Tocantins - valor de $\mathrm{R} \$$ 363.000,00 (trezentos e sessenta e três mil reais), para atender 363 (trezentos e sessenta e três) alunos.

- Ponte Alta do Bom Jesus - valor de R\$111.000, oo (cento e onze mil reais), para atender 111 (cento e onze) alunos. 
- Rio dos Bois - valor de $\mathrm{R} \$ \mathbf{1 0 6 . 0 0 0 , 0 0}$ (cento e seis mil reais), para atender 106 (cento e seis) alunos.

- Rio Sono - valor de $\mathrm{R} \$ \mathbf{6 2 . 0 0 0 , 0 0}$ (sessenta e dois mil reais), para atender 62 (sessenta e dois) alunos.

Gestão do transporte escolar em Municípios do Tocantins: distinções

Ao buscar informações a respeito da(s) possível(eis) relação(ões) entre a gestão do transporte escolar e a situação de organização da educação em municípios, ou seja, se a organização em redes de ensino ou sistema próprio de educação modifica a forma de gestão deste Programa, os municípios responderam de modo bastante distinto. Porém, a despeito das respostas distintas, chama-se a atenção para o fato de nenhum município com sistema de educação ter respondido à pesquisa. Em outras palavras, responderam a pesquisa apenas municípios que se constituem como redes de ensino do sistema estadual.

Assim, não foi possível fazer a relação entre as duas situações de gestão da educação no âmbito municipal, e sim, tratar da atuação de municípios com rede de ensino em um dos serviços básicos, não apenas suplementar, como tratam as normas nacionais da educação.

\section{Gestão Municipal do Transporte Escolar}

Em se tratando de como os municípios estão fazendo a gestão do transporte escolar, como explicitado anteriormente, apreendeu-se informações a respeito dos aspectos

planejamento/organização/administração/execução/coordenação, manutenção/financiament o, articulação com atores sociais/comunidade, acompanhamento, fiscalização e avaliação.

Para os respondentes, o planejamento acontece com o cadastro ou matrícula de cada aluno; o levantamento das distâncias de deslocamento; das condições de tráfego e 
da quantidade de alunos. Há, também, o levantamento das rotas, para averiguar onde estão localizados os alunos; e, por fim, a distribuição das rotas. Assim, acontece um diagnóstico dos roteiros escolares, abordando quilometragem, distâncias, calendário escolar, horários das aulas, turnos, condições das estradas, número de alunos por rota, condições dos veículos, conforme as especificidades de cada roteiro, e se o recurso disponível é suficiente para todas as despesas da demanda.

Para um município, a Secretaria Municipal de Educação organiza os pontos de referência para cada rota e os pontos de apoio para os motoristas.

Em relação à organização, administração e execução do transporte escolar, as respostas mostraram que a responsabilidade é da Prefeitura, algumas fazendo vistorias diárias do transporte de aluguel e do município. Esse processo acontece após a distribuição das rotas com o encaminhamento dos veículos pelo município.

Outros dois respondentes afirmam: o primeiro, que acontece conforme o calendário escolar e que a administração é de responsabilidade do secretário administrativo e a execução de acordo com a demanda; o segundo, afirma que a organização, administração e execução são realizadas em conjunto, envolvendo diretores, pais de alunos, comunidade escolar, motoristas e, em outro momento, com as Secretarias Municipais de Transportes, Finanças e Educação.

Já a coordenação, para um respondente, acontece com o controle diário de cada meio de transporte escolar, para garantir as boas condições de tráfego e a boa prestação de serviços do condutor do transporte. Dois outros respondentes afirmaram que acontece em parceria entre as Secretarias Municipais de Administração e da Educação. No entanto, um afirmou que esta responsabilidade é da Secretaria de Transporte, com o apoio da Secretaria de Educação. Por fim, um respondeu que acontece de forma contínua, diariamente e mensalmente, pelos diretores de escola e pelas Secretarias Municipais de Educação e de Transporte.

Com relação à manutenção e financiamento, para um respondente, a verba repassada é suficiente. Outros três informaram que esse processo acontece por meio de parcerias entre a Prefeitura, a Secretaria de Estado da Educação e o MEC. Por fim, em outro município, acontece de duas formas, sendo os transportes pertencentes ao poder 
público municipal, mantidos pela Secretaria Municipal de Educação, e os transportes locados, mantidos pelos proprietários dos veículos.

Ao abordar a respeito da articulação com atores sociais/comunidade, um município utiliza o mecanismo do comunicado, ou seja, que os pais são informados a procurar a Secretaria da Educação, para debater e conscientizar quanto a possíveis contratempos com transporte escolar. Outro respondente afirmou que a articulação acontece por meio de reuniões entre os Conselhos da Educação e do Fundeb, os diretores escolares, o Conselho Tutelar e a Secretaria Municipal de Educação para discussões e busca de soluções.

Utilizando o mesmo mecanismo, a reunião, outros dois afirmam que a Secretaria Municipal de Educação realiza encontro com as comunidades no início do ano letivo e, sempre que há necessidade, para esclarecimentos, recomendações e sugestões. Um deles informa que além de reuniões, acontecem visitas domiciliares pela equipe das escolas e da Secretaria da Educação. Entretanto, outro respondente destacou que é feita a conscientização da comunidade, alertando que o transporte escolar é somente para o atendimento aos alunos.

Em se tratando do acompanhamento, as respostas são variadas. Para um, as verbas destinadas ao município são acompanhadas com a participação do Conselho do Fundeb, do Conselho Municipal de Educação e por meio de reuniões, com o objetivo de informar os valores repassados, tanto federais quanto estaduais. Demais respondentes destacam: um, que esta ação é realizada pelas Secretarias Municipais de Educação e Administração; outro, que este acompanhamento é feito esporadicamente quando técnicos da Secretaria vão até as escolas ou por meio da comunicação com os motoristas; e ainda outro, que a Secretaria Municipal de Educação acompanha o Programa diariamente, pois os problemas são inúmeros, como veículos danificados, estradas ruins, brigas de alunos no interior dos veículos; e por fim, outro respondente informou que é realizado pelo monitor, que repassa as informações aos diretores das escolas e à Secretaria Municipal da Educação.

Quanto à fiscalização, os informantes não divergiram, com exceção de um que afirma que não existe esta ação da gestão. Um afirmou que é realizada pela própria 
entidade executora, a Prefeitura, junto à Secretaria da Educação e comunidade, por meio das reuniões, de vistorias dos extratos dos repasses destinados para este fim e prestação de contas à comunidade com audiência pública. Outro respondente citou a participação dos Conselhos do Fundeb e da Educação e outro dos diretores escolares.

Por fim, a avaliação concentrou informações distintas. Um respondeu que é realizada pela Secretaria Municipal de Educação, convocando os monitores do transporte escolar e exigindo boa qualidade desse transporte para o aperfeiçoamento constante e diário, principalmente, dos transportes terceirizados. Já outro, afirma que a informação foi de que a avaliação envolve a observação de documentação, que deve estar adequada e atualizada, como, por exemplo, o Imposto de Veículo Autorizado (IPVA) e o Seguro Obrigatório de Danos Pessoais Causados por Veículos Automotores de Vias Terrestres, ou por sua Carga, a Pessoas Transportadas ou Não (Seguro DPVAT), bem como a observação das condições do transporte, que devem ser boas para o uso.

Mais três informações foram coletadas acerca da questão da avaliação: um respondente afirmou que é realizada por todos os órgãos que acompanham o desenvolvimento do transporte, mas não os citaram. Outro, que a informação é de que o transporte escolar é de boa qualidade, mas que é insuficiente para atender à demanda do município. Por fim, um informou que a avaliação é realizada continuamente pela comunidade, pais, escolas e Secretaria Municipal de Educação.

Destas informações, de forma breve, pode-se concluir que o descrito no Manual de Planejamento do Transporte Escolar Rural/Cartilha do Gestor (BRASIL, 2010, p. 5, 34) representa o encontrado nos municípios tocantinenses pesquisados: "Para a grande maioria dos municípios brasileiros, a falta de estrutura organizacional e o desconhecimento de métodos e técnicas de planejamento têm ocasionado graves problemas na execução do Transporte Escolar Rural.” E continua, “[...] nem sempre os municípios conseguem executar o planejamento do Transporte Escolar Rural, o que acaba provocando desequilíbrios e ineficiência no serviço prestado." 
Dificuldades quanto à gestão do transporte escolar

Em relação ao planejamento, as dificuldades podem se resumidas da seguinte forma: a distância que alguns alunos têm que percorrer até a chegada ao transporte escolar, em especial, devido às condições precárias das estradas, sobretudo no período de chuvas; o aumento gradativo de alunos; recursos financeiros insuficientes; e a grande extensão territorial em um município.

Com a organização, administração e execução, as dificuldades são, também, as grandes distâncias e estradas ruins, que, por vezes, causam a fadiga dos alunos pelo calor e danos nos transportes; e em atender a grande demanda que, por vezes, o município não conta com um técnico disponível para esta função.

Quanto à coordenação do transporte escolar, os respondentes reclamaram da falta de contato dos motoristas com a Secretaria Municipal de Educação; da dificuldade no manejo dos veículos para atender a todos os alunos; da falta de uma equipe para coordenar o Programa. Situação que faz com que os problemas relacionados à manutenção cheguem atrasados à Secretaria Municipal de Educação.

Outro respondente, novamente, citou a necessidade de melhorar as condições das estradas. Por fim, de forma distinta, em um dos municípios, o respondente afirmou que não havia dificuldades com a coordenação, em decorrência da dedicação e responsabilidade dos condutores, bem como pela definição correta das rotas.

A manutenção/financiamento foi abordada distintamente pelos respondentes da seguinte forma:- para um, a verba repassada ao município é suficiente para as necessidades do transporte escolar; e há dificuldade quando os repasses das verbas não ocorrem nas datas previstas; - para outros dois: os recursos são insuficientes para cobrir as despesas vinculadas ao uso do transporte escolar, dentre estas, gastos com pneus, combustível, lubrificantes, locação de veículos, licenciamento; - para outro: a dificuldade é com a demora na prestação de contas dos recursos advindos das parcerias com a Secretaria Estadual de Educação e PNATE, que é realizada pelo departamento financeiro da Prefeitura; - finalizando, para outro: há falta de profissionais e de técnicos na área de manutenção mecânica no município, o que gera mais custos financeiros, uma vez que os 
veículos devem ser levados à capital do Estado. Aborda, também, que a ausência do transporte escolar na escola obriga os alunos a faltarem vários dias a aula.

Em relação à articulação com atores sociais/comunidade, as respostas se aproximaram, demonstrando a falta de contato dos pais com a coordenação do transporte escolar, para acompanhamento dos seus filhos; a dificuldade na aceitação das normas pela comunidade, como por exemplo, a proibição de caronas; a utilização indevida dos veículos por algumas comunidades, ou seja, para outras finalidades, e com a aceitação do gestor municipal, fugindo do controle da Secretaria Municipal de Educação, por não ser ouvida.

No quesito acompanhamento do transporte escolar, as dificuldades apontadas pelos respondentes foram: a falta de compromisso por parte dos conselheiros em registrar faltas às reuniões para prestação de contas; em relação à variedade de rotas existentes; pela distância entre a entidade mantenedora do Programa e as escolas, bem como pelo contato com os motoristas; o município/Prefeitura não consultar a Secretaria Municipal de Educação na tomada de decisões; em decorrência das grandes distâncias, impedindo que a Secretaria Municipal de Educação acompanhe de forma melhor o Programa.

Em se tratando da fiscalização, ocorreram as seguintes informações: - um município: de que não existe fiscalização do Programa; - em outro: que não há dificuldades, uma vez que a coordenação está diariamente vistoriando as dificuldades enfrentadas pelos motoristas; - em outros três: explicitaram suas dificuldades, sendo a falta de conhecimento da legislação em relação ao transporte por parte de alguns órgãos fiscalizadores; a distância do órgão gestor com as rotas e escolas; a distância das rotas até a Secretaria Municipal de Educação. Este último informou que, mesmo com a dificuldade, os diretores fazem o trabalho de acompanhamento e repassam as informações à Secretaria Municipal de Educação. 
Por fim, quanto à avaliação, as dificuldades também são distintas, a exemplo, o descumprimento dos deveres e da organização da documentação por alguns condutores do transporte; a falta de equipe de coordenação do Programa no município; o baixo valor de recursos repassados pelas esferas estadual e federal para o Programa em âmbito municipal.

$A(s)$ relação(ões) entre a gestão do transporte escolar e a situação de organização da educação em municípios

Ao buscar informações a respeito da(s) possível(eis) relação(ões) entre a gestão do transporte escolar e a situação de organização da educação no município, as respostas foram distintas e não permitem o estabelecimento de uma relação maior, como por exemplo, a inexistência do sistema e a deficiência do Programa.

Em um dos municípios, o respondente afirmou que há uma parceria entre Estado e Município; há uma contribuição de democratização para que os alunos que usam o transporte escolar sejam beneficiados com qualidade, para que haja uma aprendizagem de qualidade. "Por que educação de qualidade é fazer com que o município respeite o direito dos alunos ao acesso à escola". Contudo, outro respondente afirmou que os desafios são inúmeros, mas na Secretaria Municipal de Educação, pela consciência do seu papel, há a busca constante por seu cumprimento. Ainda, abordou que o relacionamento com os motoristas é considerado bom, facilitando, assim, o desempenho do trabalho no que diz respeito ao acesso às informações, que são instrumentos utilizados nas reivindicações junto ao gestor municipal. E, por fim, outro respondente afirmou que existe sim esta relação e que a maioria das escolas do município é do meio rural; portanto, dependendo literalmente dos transportes escolares.

Relação de cooperação entre o Sistema Estadual de Ensino e os Municípios para a gestão do transporte escolar

$\mathrm{Na}$ busca de informações a respeito da existência ou não de relação de cooperação, seja por meio de convênios ou outros instrumentos entre o Sistema Estadual 
de Ensino e os municípios para a gestão do transporte escolar, em especial nos municípios que não possuem sistemas próprios de educação, as respostas não foram diferentes, reafirmando a existência do instrumento Convênio.

Em dois municípios, a afirmação foi de que não existe outra relação além do repasse de verbas ao município pelas outras esferas públicas, a federal e a estadual, por meio de convênio entre a Prefeitura Municipal e a Secretaria Estadual de Educação. Em outro município, a informação foi de que existe um convênio com o Estado, mas insuficiente, ou seja, "[...] não é suficiente para cobrir as despesas gastas com o roteiro existente. Inclusive transporta alunos da escola estadual.” Encerrando esta questão, outro município, declara que "não existe" relação de cooperação.

Regulação e gestão do transporte escolar e acesso, permanência e qualidade da educação básica

Com a intenção de reunir elementos, com base nos estudos e nas experiências dos municípios investigados, de modo a subsidiar a regulação e a gestão dos serviços relacionados ao transporte escolar e, em consequência, o acesso, a permanência e a qualidade da educação básica, as dificuldades e sugestões não fugiram ao visto nas respostas anteriores.

Quanto às dificuldades, sobressaiu a insuficiência de recursos; a distância entre as residências e as rotas, causando o desgaste do tempo utilizado pelo aluno para o transporte; e a falta de escola no meio rural.

Como sugestões, as respostas resumiram que os órgãos estaduais e federais ajudem mais os municípios, em especial, na manutenção dos roteiros e aquisição de veículos.

Destacam-se algumas informações dos respondentes, tais como: - em um município: há falta de escola no meio rural, ao afirmar que "As dificuldades encontradas pelos alunos da zona rural para ter acesso à escola na zona urbana, devido à falta de escolas na zona rural. Estudante poderá sofrer muito, com o desgaste de passar horas e horas no tráfego, até chegar à escola ou a sua casa"; - dois municípios: sugeriram que os 
órgãos estaduais e federais ajudassem mais os municípios, como por exemplo, na manutenção das estradas de roteiros escolares, das pontes inacabadas e bueiros inacabados, como também disponibilizasse mais ônibus escolares ao município, pois boa parte dos transportes é terceirizada; - outro município: a resposta foi de que "Apesar da eficácia do transporte escolar [...]", outro respondente disse que no município ainda há demanda não atendida, pela distância das residências e rotas, bem como recursos insuficientes.

Das respostas à pesquisa, em uma breve análise, é possível inferir que municípios do Tocantins precisam pensar e reorganizar seus modos de gestão do seu transporte escolar, em todas as suas ações: planejamento, organização/ administração/ execução/ coordenação, manutenção/financiamento, articulação com atores sociais/comunidade, acompanhamento, fiscalização e avaliação.

$E$, nesse processo, destaca-se a necessidade do enfrentamento da discussão em relação ao processo efetivo de institucionalização do sistema municipal de educação (LAGARES, 2009), bem como dos Arranjos de Desenvolvimento da Educação (ADE) (BRASIL, 2011), visando ao regime de colaboração entre União, Estados, Distrito Federal e Municípios, de forma horizontal e articulada, para assegurar o direito à educação de qualidade nos municípios. E, ainda, visando promover a aplicação relevante dos recursos para fins idênticos ou equivalentes; e construir ações para a eliminação ou redução das desigualdades regionais e intermunicipais em relação à Educação Básica, observadas as atribuições definidas no Art. 11 da LDB nº 9.394/96 (BRASIL, 1996).

\section{Considerações finais}

Com o objetivo de investigar a relação entre o transporte escolar e os processos de institucionalização e gestão da educação municipal, em redes de ensino ou em sistemas próprios de educação, de forma amostral, no âmbito do Tocantins, de modo a subsidiar a regulação e a gestão dos serviços relacionados ao transporte escolar e, em consequência, o acesso, a permanência e a qualidade da educação básica, foi possível o 
desvelamento de aspectos considerados importantes em uma gestão educacional e que contribuem para outras problematizações em relação ao objeto investigado.

Assim, o estudo reitera a contribuição da análise de dados qualitativos relacionada à gestão do transporte escolar, para a ascensão de elementos que possam subsidiar a gestão de políticas públicas sobre o tema. O que poderá acontecer com análises mais aprofundadas das informações aqui dispostas, bem como por meio de mais pesquisas, especialmente, em relação ao revelado neste estudo.

Os cinco municípios que responderam ao questionário demonstram informações de várias regiões do Tocantins, mas, em uma breve análise, as possíveis diferenças de realidade geográficas, culturais e econômicas não demonstraram uma gestão com muitas diferenças. Na realidade, as características geográficas, a baixa densidade demográfica e o isolamento espacial destes municípios parecem contribuir com a problemática na gestão do transporte escolar.

As dificuldades e problemas com a gestão do transporte escolar podem ser resumidos em:

- Planejamento: ausência ou não informação da existência de documentos específicos, como por exemplo, planos, programas e projetos.

- Organização/administração/execução: transportes locados; veículos danificados e problemas relacionados à sua manutenção física; condições ruins/precárias das estradas, sobretudo no período de chuvas; variedade de rotas e longas distâncias até a escola; distância do órgão gestor com as rotas e escolas; distância das rotas até a Secretaria Municipal de Educação; fadiga dos alunos, pelo calor e danos nos transportes; aumento gradativo de alunos; recursos financeiros insuficientes; brigas de alunos no interior dos veículos; manejo inadequado dos veículos para atender a todos os alunos; utilização indevida dos veículos/para outras finalidades e com a aceitação do gestor municipal; falta de autonomia da Secretaria Municipal de Educação, na tomada de decisões, por não ser ouvida; distância entre a entidade mantenedora do Programa e as escolas, bem como o contato com os motoristas; descumprimento dos deveres e da organização da documentação por alguns condutores do transporte.

- Coordenação: ausência de profissional ou de equipe para desenvolver a função de 
coordenação.

- Manutenção/financiamento: recursos insuficientes para todas as despesas; repasses atrasados das verbas; demora na prestação de contas dos recursos, que normalmente é feita Secretaria Municipal de Administração e Finanças; os tradicionais convênios e parcerias, não há visão de cooperação articulada e sistemática.

- Articulação com atores sociais/comunidade: contato com os pais por meio de comunicados; realização de reuniões apenas no início do ano letivo, não de forma sistemática; falta de contato dos pais com a coordenação do transporte escolar, para acompanhamento dos seus filhos; dificuldade na aceitação das normas pela comunidade; ausência de uma melhor relação de cooperação entre o Sistema Estadual de Ensino e os Municípios para a gestão do transporte escolar.

- Acompanhamento: acompanhamento esporádico.

- Fiscalização: inexistência de fiscalização ou concentração apenas nas vistorias dos extratos dos repasses financeiros; falta de compromisso por parte de conselheiros do Fundeb, que faltam às reuniões para prestação de contas; desconhecimento da legislação em relação ao transporte por parte de alguns órgãos fiscalizadores.

- Avaliação: ausência de avaliação ou ações não sistemáticas, contínuas.

Dois aspectos desvelados pela pesquisa merecem destaque por sua importância, tanto na concepção quanto na operacionalização da gestão. O primeiro, a crença de que o transporte escolar é um benefício, e não um direito de todos. O segundo é a tradicional inversão de pensamento em relação ao financiamento da educação, ou seja, de que o recurso disponível deve ser suficiente para todas as despesas com as demandas, e não o contrário, de que as demandas é que devem definir os recursos.

Por fim, as sugestões concentram-se na melhoria das condições das estradas, bueiros e pontes e em mais repasses financeiros ao município pelas esferas estadual e federal, para o transporte escolar.

Assim posto, não foi possível identificar, como sugestões para melhorar o transporte, ações como a organização de um plano de ação, construído de forma participativa; o diálogo permanente com todas as esferas e, em especial, entre a Secretaria Municipal de Educação e as outras secretarias municipais envolvidas com o 
transporte escolar e entre estes e a comunidade; e o acompanhamento, a fiscalização e a avaliação permanentes e com instrumentos específicos.

Concluindo, como todos os municípios que responderam ao questionário constituem-se como rede de ensino do Sistema de Ensino do Tocantins, defende-se a necessidade do enfrentamento da discussão em relação ao processo efetivo de institucionalização do sistema municipal de educação como instrumento de gestão pública para assegurar o direito à educação de qualidade social nos municípios. O que significa a garantia do padrão de qualidade, o pleno acesso, a inclusão, a permanência, a aprendizagem e a conclusão da educação infantil e do ensino fundamental de nove anos, com redução da evasão, da retenção e da distorção idade-ano/série.

\section{Referências}

BRASIL. Assembleia Constituinte. Constituição Federal de 1988, de 5 de outubro de 1988. Brasília, 1988. Disponível em: <http://www.planalto.gov.br>. Acesso em: 10 de ago. 2011.

BRASIL. Câmara dos Deputados. Consultoria Legislativa. Plano Nacional de Transporte Escolar. Nota Técnica. Helena Heller Domingues de Barros (Consultora legislativa da área XV Educação, Desporto, Bens Culturais, Diversões e Espetáculos Públicos). Brasília, 2001. Disponível em: <http://www.planalto.gov.br>. Acesso em: 21 de ago. 2011.

BRASIL. Conselho Nacional de Educação. Câmara de Educação Básica. Parecer nº9, de 30 de agosto de 2011. Análise de proposta de fortalecimento e implementação do regime de colaboração mediante arranjos de desenvolvimento da educação. Brasília, 2011. Disponível em: <http://www.mec/cne.gov.br>. Acesso em: 11 de out. 2011.

BRASIL. Congresso Nacional. Lei nº 9.394, de 20 de dezembro de 1996. Estabelece as diretrizes e bases da educação nacional. Brasília, 1996. Disponível em: <http://www.planalto.gov.br>. Acesso em: 10 de ago. 2011.

BRASIL. Congresso Nacional. Lei $\mathbf{n}^{\circ} \mathbf{1 0 . 7 0 9}$, de 31 de julho de 2003. Acrescenta incisos aos arts. 10 e 11 da Lei $n^{\circ}$ 9.394, de 20 de dezembro de 1996, que estabelece as diretrizes e bases da educação nacional e dá outras providências. Brasília, 2003. Disponível em: <http://www.planalto.gov.br>. Acesso em: 10 de ago. 2011.

BRASIL. Congresso Nacional. Lei $\mathbf{n}^{\mathbf{1}} \mathbf{1 0 . 8 8 0}$, de 09 de junho de 2004. Institui o Programa Nacional de Apoio ao Transporte do Escolar - PNATE e o Programa de Apoio aos Sistemas de Ensino para Atendimento à Educação de Jovens e Adultos, dispõe sobre o repasse de 
recursos financeiros do Programa Brasil Alfabetizado, altera o art. $4^{\circ}$ da Lei $n^{\circ}$ 9.424, de 24 de dezembro de 1996, e dá outras providências. Brasília, 2004. Disponível em: <http://www.planalto.gov.br>. Acesso em: 10 de ago. 2011.

BRASIL. Congresso Nacional. Lei $\mathbf{n}^{\circ} \mathbf{1 1 . 9 4 7}$, de 16 de junho de 2009. Dispõe sobre o atendimento da alimentação escolar e do Programa Dinheiro Direto na Escola aos alunos da educação básica; altera as Leis $n^{\circ}$ 10.880, de 9 de junho de 2004, 11.273, de 6 de fevereiro de 2006, 11.507, de 20 de julho de 2007; revoga dispositivos da Medida Provisória $n^{\circ}$ 2.178-36, de 24 de agosto de 2001, e a Lei $n^{\circ} 8.913$, de 12 de julho de 1994; e dá outras providências. Brasília, 2009. Disponível em: <http://www.fnde.gov.br>. Acesso em: 10 de ago. 2011.

BRASIL. Ministério da Educação. Fundo Nacional de Desenvolvimento da Educação. Centro de Formação de Recursos Humanos em Transportes (Ceftru). Universidade de Brasília (UnB). Manual de planejamento do transporte Escolar rural / cartilha do gestor. Brasília, 2010. Disponível em: <http://www.fnde.gov.br>. Acesso em: 11 de out. 2011.

BRASIL. Ministério da Educação. Fundo Nacional de Desenvolvimento da Educação. Resolução $\mathbf{n}^{\circ}$ 3, de 28 de março de 2007. Cria o Programa Caminho da Escola e estabelece as diretrizes e orientações para que os municípios e estados possam buscar financiamento junto ao Banco de Desenvolvimento Social e Econômico - BNDES para aquisição de ônibus, mini-ônibus, micro-ônibus e embarcações enquadrados no Programa, no âmbito da Educação Básica. Brasília, 2007. Disponível em: <http://www.fnde.gov.br>. Acesso em: 10 de ago. 2011.

BRASIL. Ministério da Educação. Instituto Nacional de Estudos e Pesquisas Educacionais Anísio Teixeira (INEP). Censo escolar de 2013. Brasília, DF, 2013. Disponível em <www.inep.gove.br>. Acesso em: 07/10/2014.

ESTELLES, Reinaldo Soares; RIBEIRO, Rejane Arruda. A pesquisa transporte escolar rural: levantando dados qualitativos como subsídio às políticas públicas. 2009. Disponível em www.cbtu.gov.br/monografia/2009/trabalhos/artigos/.../3_356_AC.pdf. Acesso em 2 de set. de 2011.

FEIJÓ, Patrícia Collat Bento. Transporte escolar. A obrigação do poder público municipal no desenvolvimento do programa. Aspectos jurídicos relevantes. 2007. Disponível em: www.mp.sp.gov.br/portal/page/.../Texto\%20-\%20Transporte\%20escolar. ISSN 1983-4640. Acesso: 12 de ago. de 2011.

GEIPOT. Empresa Brasileira de Planejamento de Transporte. Avaliação preliminar do transporte rural - destaque para o segmento rural. Brasília, DF, 1995. 
LAGARES, Rosilene. Sistema Municipal de Educação: idéias quanto a elementos constitutivos para a sua institucionalização. In: REUNIÃO ANUAL DA ANPED $32^{\circ}$, Caxambu (MG), 04 a 07 out., 2009. Anais..., Local: ANPED, 2009.

LAGARES, Rosilene. Gestão da educação: o desafio da cultura da ética, da democracia, da qualidade para todos. Tempo Integral: Revista de Educação da Prefeitura de Palmas. Ano 1 n.3, p. 51-55, Jul./set., de 2005. ISSN 1808-2890.

MARTINS, Ana Paula Antunes. Análise dos impactos das condições do transporte escolar rural no rendimento escolar dos alunos. 2010, 00 f. Dissertação (Mestrado em Transporte). Universidade de Brasília, DF, . Departamento de Engenharia Civil e Ambiental. Brasília (DF), 2010. Publicação T. DM- 007A/2010

SANTOS, Tatiana Monteiro Marques dos. Transporte escolar rural na perspectiva de gestores e planejadores/operadores: subsídios para políticas públicas. Universidade de Brasília. Instituto de Ciência Política. Programa de Pós-Graduação em Ciência Política. Brasília, 2010. Disponível em:

<http://repositorio.bce.unb.br/bitstream/10482/7178/1/2010_TatiaraMonteiroMarquesdosS antos.pdf>. Acesso: 12 de ago. de 2011.

TOCANTINS. Secretaria Estadual de Educação do Tocantins. Regra de cálculo do Programa de Manutenção do Transporte Escolar - 2014. Palmas, Tocantins, $2014 a$. Disponível em: <www.seduc.to.gov.br >. Acesso em 07/10/2014.

TOCANTINS. Secretaria Estadual de Educação do Tocantins. Programa Manutenção do Transporte Escolar : plano de aplicação / cronograma de desembolso. Palmas, Tocantins, 2014b. Disponível em: <www.seduc.to.gov.br>. Acesso em 07/10/2014.

TOCANTINS. Universidade Federal do Tocantins (UFT). Relatório de pesquisa transporte escolar: pesquisa nacional custo aluno. Universidade de Brasília (UnB)/Universidade Federal do Tocantins (UFT)/ Núcleo de Estudos Contemporâneos (Necon UFT). Palmas, 2012. Mimeo. 
Recebido em: 20/02/2014 Aprovado em: 29/09/2014

Universidade do Estado de Santa Catarina - UDESC

Centro de Ciências Humanas e da Educação - FAED

Revista PerCursos

Volume 15 - Número 29 - Ano 2014 revistapercursos@gmail.com 